\title{
Synthesis and characterization of titanium oxide nanomaterials using sol-gel method
}

\author{
Stotaw Talbachew Hayle ${ }^{1}$, Girma Goro Gonfa ${ }^{2}$ \\ ${ }^{1}$ Department of Physics, College of Natural and Computational Science, Mizan Tepi University, Tepi, Ethiopia \\ ${ }^{2}$ Department of Physics, Haramaya University, P.O.Box 138, Dire Dawa, Ethiopia
}

Email address:

stotaw19@gmail.com (S. T. Hayle),girmag@gmail.com (G. G. Gonfa)

To cite this article:

Stotaw Talbachew Hayle, Girma Goro Gonfa. Synthesis and Characterization of Titanium Oxide Nanomaterials Using Sol-Gel Method. American Journal of Nanoscience and Nanotechnology. Vol. 2, No. 1, 2014, pp. 1-7. doi: 10.11648/j.nano.20140201.11

\begin{abstract}
This paper reports the effect of temperature on the properties of $\mathrm{TiO}_{2}$ nanomaterials, synthesis and characterization. $\mathrm{TiO}_{2}$ powders were synthesized by sol-gel method using $\mathrm{TiCl}_{4}$ solution added in deionized water in ice bath under fume hood followed by the addition of ethanol with vigorous stirring for $30 \mathrm{~min}$ at room temperature. The gel solution was obtained and then got dried using oven at $200^{\circ} \mathrm{C}$ for 4 hours. Then, the dried gel was calcinated at $250^{\circ} \mathrm{C}$, $400^{\circ} \mathrm{C}$ and $600^{\circ} \mathrm{C}$ using furnace for 4 hours each. The synthesized $\mathrm{TiO}_{2}$ nanomaterials were characterized by XRD, UV-Vis spectrophotometer, Transmission electron microscope (TEM), Scanning electron microscope (SEM), Energy dispersive spectroscopy (EDS). XRD shows the particles size with high crystallinity and purity which is in good agreement with the TEM result. The particles size of the synthesized $\mathrm{TiO}_{2}$ nanomaterial at calcination temperatures of $250^{\circ} \mathrm{C}, 400^{\circ} \mathrm{C}$ and $600^{\circ} \mathrm{C}$ were $9.22 \mathrm{~nm}, 14.33 \mathrm{~nm}$ and $36.72 \mathrm{~nm}$ respectively calculated from XRD result. The absorption edge for $\mathrm{TiO}_{2}$ nanomaterials synthesized by sol gel synthesis method was found to be $350 \mathrm{~nm}$ and the corresponding calculated band gap energy was $3.54 \mathrm{eV}$. The average particles size of the synthesized $\mathrm{TiO}_{2}$ nanopowder investigated from TEM using histograms at calcination temperatures of $250^{\circ} \mathrm{C}, 400^{\circ} \mathrm{C}$ and $600^{\circ} \mathrm{C}$ were found $(8.55 \pm 0.25) \mathrm{nm},(13.82 \pm 0.41) \mathrm{nm}$ and $(36.06 \pm 2.03) \mathrm{nm}$ respectively. The polygonal structure of $\mathrm{TiO}_{2}$ nanomaterials were studied by scanning electron microscope. The EDS result showed that at calcination temperatures of $250^{\circ} \mathrm{C}, 400^{\circ} \mathrm{C}$ and $600^{\circ} \mathrm{C}$, the concentrations of titanium were $33.34 \%, 32.6 \%$ and $31.89 \%$, and the concentrations of chlorine were $2.64 \%, 0 \%$ and $0 \%$, and the concentrations of oxygen were $64.02 \%, 67.4 \%$ and $68.11 \%$ in the synthesized $\mathrm{TiO}_{2}$ nanopowder respectively which is qualitatively confirmed by energy dispersive $\mathrm{x}$-ray spectroscopy results.
\end{abstract}

Keywords: Spectroscopy, Sol Gel Synthesis, $\mathrm{TiO}_{2}$ Nanomaterial

\section{Introduction}

Nanocrystalline semiconductors have achieved a great importance in our industrial world today. They are cornerstones of nano-scale science and nanotechnology. Nanostructure science and technology is a broad and interdisciplinary area of research and development activity that has been growing explosively worldwide in the past decade [2]. It has the potential for revolutionizing the ways in which materials and products are created and the range and nature of functionalities that can be accessed. It is already having a significant commercial impact, which will assuredly increase in the future. Nanomaterials are defined as a set of substances where at least one dimension is less than approximately 100 nanometers.

Nanomaterials have a broad spectrum of applications.
Today they are contained in many products and used in various technologies. Most nanoproducts produced on an industrial scale are nanomaterials, although they also arise as by products in the manufacture of medicine [9]. Nanomaterials are emerging family of novel materials that could be designed for specific properties. The various properties: - optical, physical, chemical and electrical could be tailored for specific applications. Nanoparticle reenforced polymers may be used to replace metallic components in automobile industry for reduced fuel consumption and $\mathrm{CO}_{2}$ emission.

Semiconductors such as: $\mathrm{TiO}_{2}, \mathrm{ZnO}, \mathrm{Fe}_{2} \mathrm{O}_{3}, \mathrm{CdS}$, and $\mathrm{ZnS}$ can act as sensitizers for light reduced redox processes due to their electronic structure, which is characterized by a filled 
valence band and an empty conduction band. $\mathrm{TiO}_{2}$ nanomaterials have one of great attractive significant interesting materials for scientists and physicists due to their properties and widely used in many technological applications. It has the advantage of being cheap, nontoxic and stable. It has proven to be one of the promising n-type semiconductors which have many attractive properties [7]. These properties include high refractive index, high dielectric constant, chemical stability and wide band gap [1].

Titanium dioxide $\left(\mathrm{TiO}_{2}\right)$ nanomaterials have been widely studied in the last two decades [2]. Due to their versatile properties, $\mathrm{TiO}_{2}$ nanomaterials have possessed themselves vast applications, including paint, toothpaste, UV protection, photocatalysis, photovoltaics, electrochromics, as well as photochromics.

Materials in the nanometer scale, such as colloidal dispersions and thin films, have been studied over many years and many physical properties related to the nanometer size, such as coloration of gold nanoparticles, have been known for centuries. One of the critical challenges faced currently by researchers in the nanotechnology and nanoscience fields is the inability and the lack of instruments to observe and measure, and manipulate the materials at the nanometer level by manifesting at the macroscopic level. In the past, the studies have been focused mainly on the collective behaviors and properties of nanostructures of $\mathrm{TiO}_{2}$ materials. A better fundamental understanding and various potential applications increasingly demand the ability and instrumentation to observe and measure, and manipulate the individual nanomaterial of $\mathrm{TiO}_{2}$ and nanostructures of $\mathrm{TiO}_{2}$.

In the process of synthesis of $\mathrm{TiO}_{2}$, the shape and crystal structure of the product significantly depends on raw material used. Characterization and manipulation of individual nanostructures of $\mathrm{TiO}_{2}$ require not only extreme sensitivity and accuracy, but also atomic-level resolution. Therefore, this leads to various microscopes that would play a central role in characterization and measurements of nanostructures of $\mathrm{TiO}_{2}$ materials.

In the present study, the most convient ways of synthesizing various nanomaterials have preferable due to low cost, ease fabrication and low temperature. This method has various advantages over other method, such as coprecipation or allowing impregnation, which can be achieved by introducing dopant, molecular scale mixing, high purity of the precursors and homogeneity of sol-gel products with high purity physical, morphological and chemical properties of nanomaterial. Therefore, that was the reason why sol gel synthesis method is preferred as the method of titanium dioxide nanomaterials synthesis.

\section{Methods}

\subsection{Chemicals}

In this study the following chemicals were used: $\mathrm{TiCl}_{4}$ (MW 189.87. $\mathrm{gmol}^{-1}, 99.9 \%$ ), Ethanol, $\mathrm{CH}_{3} \mathrm{CH}_{2} \mathrm{OH}$ (MW $58.03 \mathrm{gmol}^{-1}$, Abron Chemicals, 99.8\%), $\mathrm{AgNO}_{3}$ (MW $\left.169.87 \mathrm{gmol}^{-1}, 98.4 \%\right)$, Ammonium hydroxide, $\mathrm{NH}_{4} \mathrm{OH}$ (MW, 17.03 $\mathrm{gmol}^{-1}, 25 \%$ ).

\subsection{Method of Preparation of $\mathrm{TiO}_{2}$ Nanomaterials}

Titanium tetra chloride $\left(\mathrm{TiCl}_{4}\right)$ of $3.5 \mathrm{ml}$ was added to 50 $\mathrm{ml}$ deionized water in ice bath and the process was done under fume hood followed by the addition of $35 \mathrm{ml}$ of ethanol with vigorous stirring for $30 \mathrm{~min}$ at room temperature. Drops of ammonium hydroxide were added wisely into solution of the titanium tetra chloride $\left(\mathrm{TiCl}_{4}\right)$, ethanol and deionized water to neutralize it and precipitate was obtained. After stirring vigorously, the solution was made to settle for twelve hours. Then, precipitate was centrifuged. The obtained precipitate was washed with deionized water until the removals of chloride ion and was centrifugally separated. Then, using oven, the precipitate was dried at $200^{\circ} \mathrm{C}$ to remove part of the absorbed water for 4 hours and finally amorphous $\mathrm{TiO}_{2}$ was obtained. The obtained amorphous $\mathrm{TiO}_{2}$ was calcinated at the temperatures of $250^{\circ} \mathrm{C}, 400^{\circ} \mathrm{C}$ and $600^{\circ} \mathrm{C}$ for four hours step by step. Finally, the powder $\mathrm{TiO}_{2}$ nanomaterial was obtained $[11,8,10]$.

\subsection{Methods of Characterization of $\mathrm{TiO}_{2}$ Nanomaterials}

There are a large number of methods to characterize $\mathrm{TiO}_{2}$ nanomaterials. The most common methods used in this work were: powder x-ray diffraction (XRD), Ultravioletvisible spectrometer, Transmission electron microscope (TEM), Scanning electron microscope (SEM) and Energy dispersive $\mathrm{x}$-ray spectroscopy to study percentage yield of element, the crystal structure, defect structure, chemical analysis, and phase identification, crystal or grain size and morphological properties.

\section{Results and Discussion}

\subsection{Powder Preparation of $\mathrm{TiO}_{2}$ Nanomaterials}

When $3.5 \mathrm{ml}$ of $\mathrm{TiCl}_{4}$ solution was added to $50 \mathrm{ml}$ of deionized water under fume hood, an exothermic reaction were observed. Then, a white precipitate was obtained after adding a drop of ammonium hydroxide $\left(\mathrm{NH}_{4} \mathrm{OH}\right)$ wisely; and the yellow gel rose. The gel being yellow indicates the formation of $\mathrm{Ti}(\mathrm{OH})_{4}$. After stirring the solution using magnetic stirrer for $30 \mathrm{~min}$ and settling for 12 hours, the precipitate was centrifuged. Then, the obtained precipitate was placed in an oven at $200^{\circ} \mathrm{C}$ for 4 hours in order to dry, which leads to the formation of white amorphous $\mathrm{TiO}_{2}$; after cooling at room temperature, the amorphous white $\mathrm{TiO}_{2}$ was obtained. The obtained amorphous white $\mathrm{TiO}_{2}$ was placed in furnace at $250{ }^{\circ} \mathrm{C}, 400^{\circ} \mathrm{C}$ and $600^{\circ} \mathrm{C}$ for 4 hours step by step to calcinate it. This calcination leads to the formation of white powder $\mathrm{TiO}_{2}$. After cooling at room temperature, the product was ground using agate mortar. Finally, the ground $\mathrm{TiO}_{2}$ powder was subjected to calcination temperatures of $250^{\circ} \mathrm{C}, 400^{\circ} \mathrm{C}$ and $600^{\circ} \mathrm{C}$ respectively so that it could be labeled and kept for further study. 


\subsection{Powder X-Ray Diffraction (XRD) Characterization of $\mathrm{TiO}_{2}$ Nanomaterials}

Powder X-ray diffraction (XRD) was used for identification of the particles size, crystal structures, crystal orientation and lattice parameter. X-ray powder diffraction (XRD) was used to characterize the titanium dioxide powder at different temperatures and to determine particles structure and crystal size.

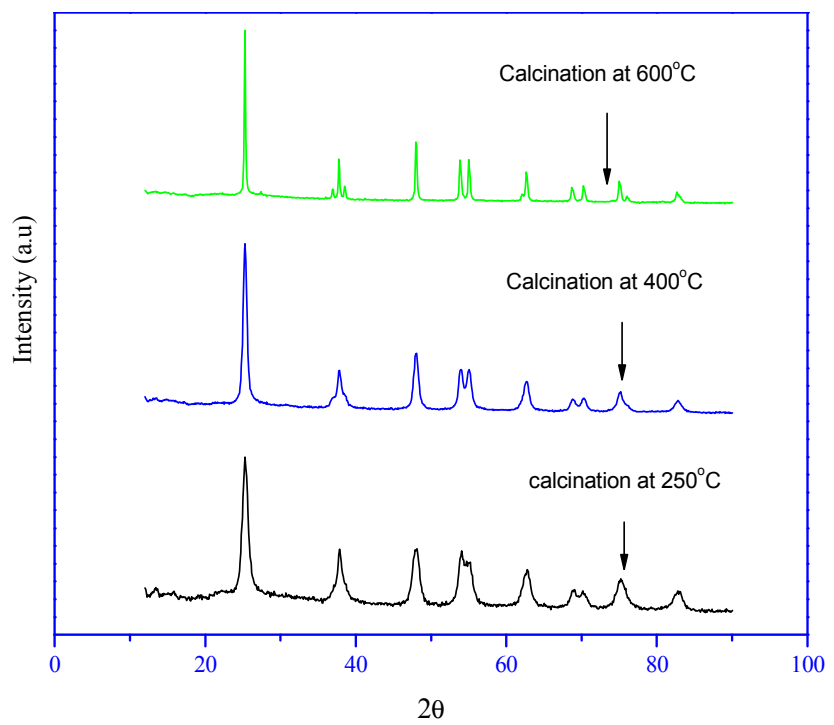

Figure 1. The XRD pattern of $\mathrm{TiO}_{2}$ nanomaterials calcination temperatures at $250^{\circ} \mathrm{C}, 400^{\circ} \mathrm{C}$ and $600^{\circ} \mathrm{C}$

As can be observed from figure 1, the XRD peaks in the angle range of $12^{\circ} \leq 2 \theta \leq 90.027^{\circ}$ determined that peaks for $250^{\circ} \mathrm{C}$ are $13.26^{\circ}, 15.74^{\circ}, 25.31^{\circ}, 30.71^{\circ}, 37.85^{\circ}, 48.17^{\circ}$, $54.05^{\circ}, 62.73^{\circ}, 69.00^{\circ}, 75.17^{\circ}, 82.79^{\circ}$, the peaks for $400^{\circ} \mathrm{C}$ are $25.31^{\circ}, 37.84^{\circ}, 48.07^{\circ}, 55.11^{\circ}, 62.62^{\circ}, 70.25^{\circ}, 75.17^{\circ}$, $82.79^{\circ}$ and the peaks for $600^{\circ} \mathrm{C}$ are $25.31^{\circ}, 37.75^{\circ}, 38.52^{\circ}$, $47.98^{\circ}, 55.02^{\circ}, 62.64^{\circ}, 74.98^{\circ}$ and $82.69^{\circ}$. Among the XRD peaks, the width of $25.31^{0}$ is useful peak since it has high intensity which in turn is used to determine crystals size. The peak value corresponds to the tetragonal anatase phase. The highest intensity was achieved for $25.31^{\circ}$ at temperature of $600^{\circ} \mathrm{C}$ and lowest intensity of $25.31^{\circ}$ was achieved at a temperature of $250^{\circ} \mathrm{C}$. The intense sharp peak indicated that the crystalline phase of anatase $\mathrm{TiO}_{2}$ was successfully formed. One can understand from figure 1 that, the intensity of the diffraction signal increases with increasing the calcination temperature. This indicates that the concentration of the particles increases.

From the XRD pattern, the crystallite sizes of the synthesized $\mathrm{TiO}_{2}$ nanomaterials were estimated using Scherere equation $[4,6,12]$.

$$
\mathrm{d}=\frac{\lambda k}{\beta \cos \theta}
$$

where,

$\mathrm{d}$ is crystallite size in nanometer $k$ is shape factor constant, which is 0.89

$\beta$ is the full width at half maximum (FWHM) in radian

$\lambda$ is the wave length of the X-ray which is $0.15406 \mathrm{~nm}$ for $\mathrm{Cu}$ target $\mathrm{K} \alpha$ radiation and

$\theta$ is the Bragg angle.

Using equation (2) the estimated crystalline size is given in the following table.

Table 1. Crystallite size (d) of the synthesized $\mathrm{TiO}_{2}$ nanomaterials calcination temperatures at $250^{\circ} \mathrm{C}, 400^{\circ} \mathrm{C}$ and $600^{\circ} \mathrm{C}$

\begin{tabular}{cccc}
\hline $\begin{array}{c}\text { Calcinations temperature } \\
\text { of samples }\left({ }^{\circ} \mathbf{C}\right)\end{array}$ & $\begin{array}{c}\mathbf{2} \boldsymbol{7} \\
(\text { degrees) }\end{array}$ & $\boldsymbol{\beta}$ (radians) & $\begin{array}{c}\text { Crystalline } \\
\text { size (nm) }\end{array}$ \\
\hline 250 & $25.31^{\circ}$ & 0.01491 & 9.22 \\
400 & $25.31^{\circ}$ & 0.009643 & 14.33 \\
600 & $25.31^{\circ}$ & 0.003748 & 36.72 \\
\hline
\end{tabular}

As shown in table1 and figure 1, increasing particles size has direct relation to calcination temperature and inverse relation to FWHM. The sharp peaks by XRD pattern show the crystallinity and purity of titanium dioxide nanomaterial This exactly matches with Scherere equation. The crystallite size $(\mathrm{nm})$ increased as the synthesis temperatures increased from $250^{\circ} \mathrm{C}$ to $400^{\circ} \mathrm{C}$ and $400^{\circ} \mathrm{C}$ to $600^{\circ} \mathrm{C}$.

\subsection{Ultra Violet-Visible Spectrometer of TiO Nanomaterials}

The bandgap energy $\left(\mathrm{E}_{\mathrm{g}}\right)$ of the synthesized $\mathrm{TiO}_{2}$ nanomaterials was obtained using the equation [3].

$$
\mathrm{E}_{\mathrm{g}}=\frac{1240}{\lambda} \mathrm{ev}
$$

where $E_{g}$ is the band gap in electron volt $(\mathrm{eV})$ and $\lambda$ is the wavelength of the absorption edges in the spectrum in nanomater (nm).

As observed in figure 2 and 3 , the UV-Vis spectra from synthesized $\mathrm{TiO}_{2}$ nanomaterials show the absorbance to be below $350 \mathrm{~nm}$. Using equation (3) the calculated value for the band gap energy of the synthesized $\mathrm{TiO}_{2}$ nanomaterials is $3.54 \mathrm{eV}$.

The graph which corresponds to the statements above is given below.

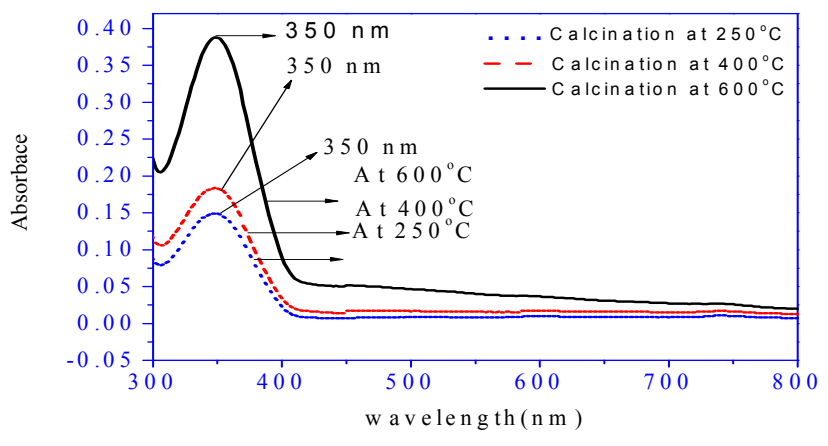

Figure 2. UV-Visible spectrum of synthesized $\mathrm{TiO}_{2}$ nanomaterials dispersed in hot deionized water at calcinations of $250^{\circ} \mathrm{C}, 400^{\circ} \mathrm{C}$ and $600^{\circ} \mathrm{C}$ 


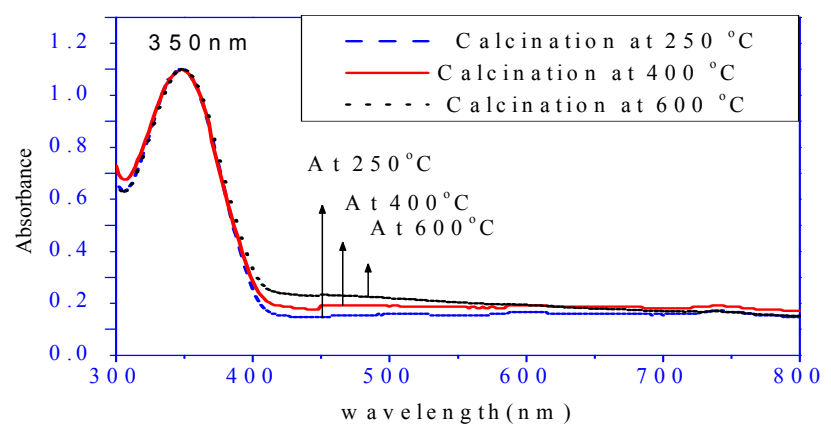

Figure 3. UV-Visible spectrum of synthesized $\mathrm{TiO}_{2}$ nanomaterials dispersed in hot deionized water normalized graph calcination temperatures at $250^{\circ} \mathrm{C}, 400^{\circ} \mathrm{C}$ and $600^{\circ} \mathrm{C}$

The synthesized $\mathrm{TiO}_{2}$ nanomaterials band gap energy $(3.54 \mathrm{eV})$ are larger than the value of $3.2 \mathrm{eV}$ for the bulk $\mathrm{TiO}_{2}$ nanomaterials. This is true due to the fact that the band gap of the semiconductors has been found to be particle size dependent $[5,10]$. The band gap increases with decreasing particle size and the absorption edge is shifted to a higher energy (blue shift) with decreasing particle size.
The band gap values validates our crystallite size results according to which smaller crystallite size should have larger band gap and large crystallite size should have smaller band gap.

As figure 2 and 3 clearly shows that the wavelength corresponding to the absorbance edge of $\mathrm{TiO}_{2}$ nanomaterial with calcination temperatures at $250^{\circ} \mathrm{C}, 400^{\circ} \mathrm{C}$ and $600^{\circ} \mathrm{C}$ is the same $(350 \mathrm{~nm})$ and the concentration measurement of the absorbance increased as the calcination temperature is increases.

\subsection{Transmission Electron Microscope (TEM)}

Transmission electron microscope (TEM) was used to study the crystal structure, morphology, shapes and particle size. Figure 4 clearly showed that polygonal structure, shapes and particle size of $\mathrm{TiO}_{2}$ nanomaterial were dependent on the calcination temperatures. When the calcination temperatures increased the shapes of the $\mathrm{TiO}_{2}$ nanomaterials leads to spherical.
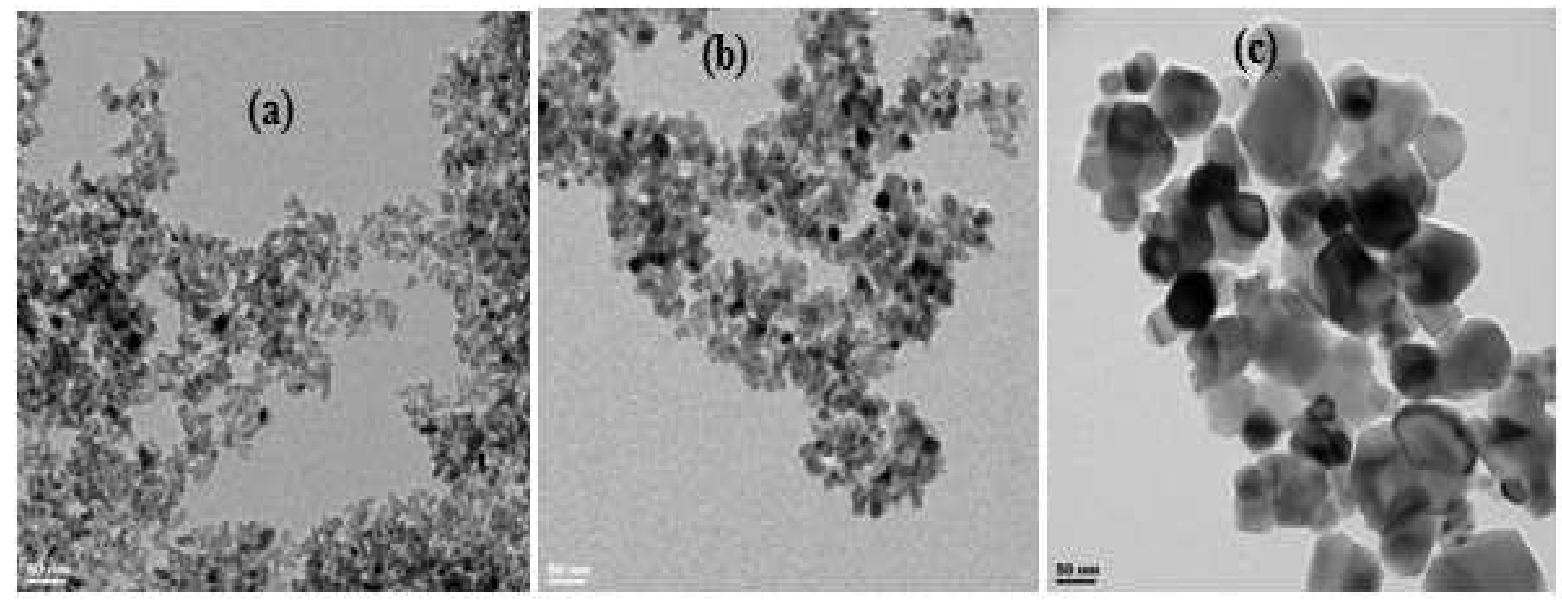

Figure 4. The TEM images of the synthesized $\mathrm{TiO}_{2}$ nanomaterials (a) calcination of $250^{\circ} \mathrm{C}$, (b) calcination of $400^{\circ} \mathrm{C}$ and (c) calcination of $600^{\circ} \mathrm{C}$

As observed from figure 4 (a) of $\mathrm{TEM} \mathrm{TiO}_{2}$ nanomaterials calcination at temperature of $250^{\circ} \mathrm{C}$, consists of particles with unfortunate fusion and aggregation. Again, observed from figure 4 (a) and 4 (b) when the calcination temperature of $250^{\circ} \mathrm{C}$ the size of the nanoparticles uniform compare with calcination temperatures of $400^{\circ} \mathrm{C}$. As the calcination temperature increased to $600^{\circ} \mathrm{C}$, the sizes of particle are no quite uniform compared with calcination temperatures of $250^{\circ} \mathrm{C}$ and $400^{\circ} \mathrm{C}$ as observed from figure 4 (c). It was learnt from figure 4 that, an increase in calcination temperatures leads to increase particle size, particles fusion and aggregation.

The size distribution was obtained by measuring each particle diameter. The random orientation of particles allows for a statistical measure of the size distribution to be generated. As it is clearly shown in figures 5,6 and 7, the synthesized $\mathrm{TiO}_{2}$ nanomaterial average particles size at a calcination temperatures of $250^{\circ} \mathrm{C}, 400^{\circ} \mathrm{C}$ and $600^{\circ} \mathrm{C}$ are $8.55 \mathrm{~nm}, 13.82 \mathrm{~nm}$ and $36.06 \mathrm{~nm}$ and the estimated errors at a calcination temperatures of $250^{\circ} \mathrm{C}, 400^{\circ} \mathrm{C}$ and $600^{\circ} \mathrm{C}$ are $\pm 0.25 \mathrm{~nm}, \pm 0.41 \mathrm{~nm}$ and $\pm 2.03 \mathrm{~nm}$ respectively. Again, from figures 5, 6 and 7, we observe that the particles size increase with increasing calcination temperature.

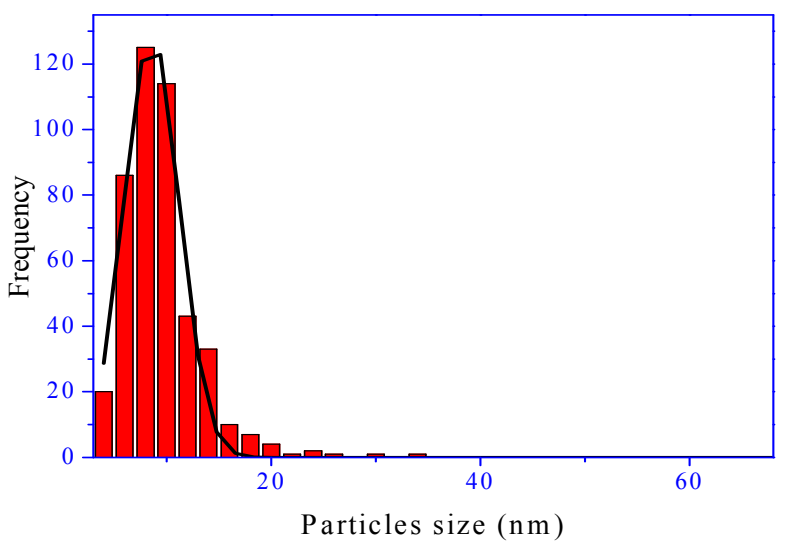

Figure 5. Particles size distribution of synthesized $\mathrm{TiO}_{2}$ nanomaterials at calcination temperature of $250^{\circ} \mathrm{C}$ 


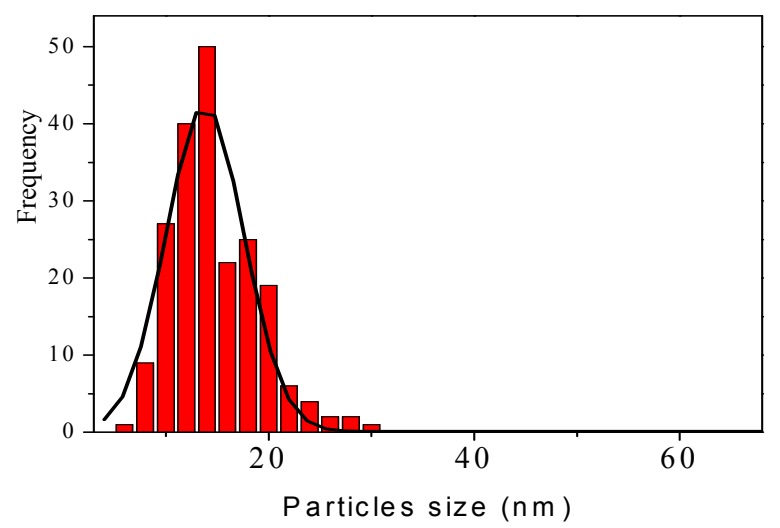

Figure 6. Particles size distribution of synthesized $\mathrm{TiO}_{2}$ nanomaterials at calcination temperature of $400^{\circ} \mathrm{C}$

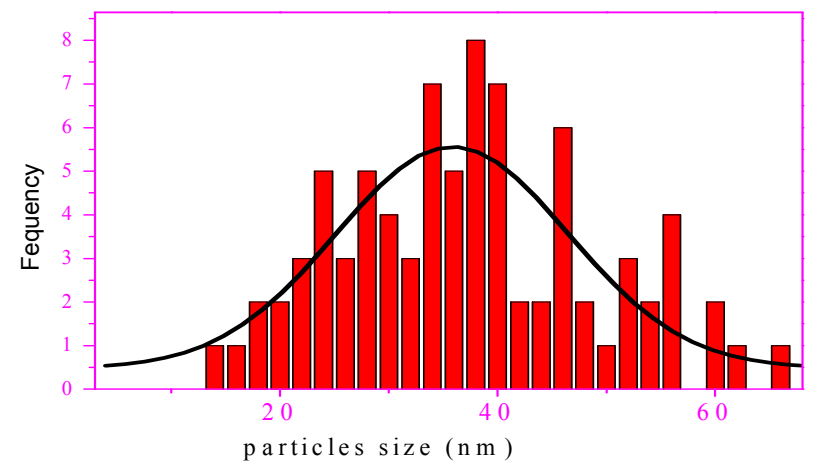

Figure 7. Particles size distribution of synthesized $\mathrm{TiO}_{2}$ nanomaterials at calcination temperature of $600^{\circ} \mathrm{C}$

\subsection{Scanning Electron Microscope (SEM)}

Scanning electron microscopy (SEM) studies were used to examine morphology and shape of nanomaterials. The EDS (Energy dispersive x-ray spectroscopy) was connected to the SEM machine and used to study the elemental composition of our sample.
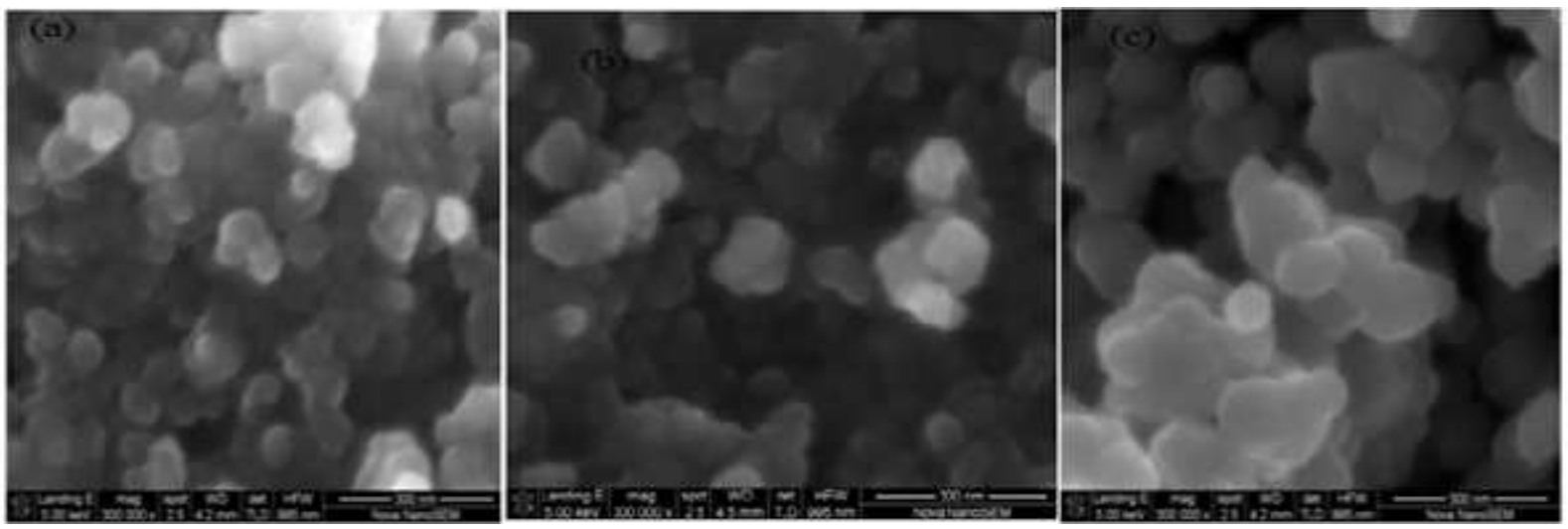

Figure 8. The SEM images of the synthesized $\mathrm{TiO}_{2}$ nanomaterials (a) calcination of $250^{\circ} \mathrm{C}$, (b) calcination of $400^{\circ} \mathrm{C}$ and (c) calcination of $600^{\circ} \mathrm{C}$

As shown from figure 8 , as the calcination temperatures increases the size of the nanoparticles is also increases. This figure shows high homogeneity emerged in sample by increasing the calcination temperature. Whatever the calcination temperature was low, the samples were less agglomerated. With increasing the calcination temperature boundaries between nanoparticles were better and the morphology of particles changed to spherical shape and the nanopowder were more agglomerated.

\subsection{Energy Dispersive X-Ray Spectroscopy (EDS)}

Energy dispersive $\mathrm{x}$-ray spectroscopy (EDS) is an analytical technique used for the elemental analysis or chemical characterization of a sample. Energy Dispersive Spectroscopy (EDS) allows one to identify what those particular elements are and their relative proportions (Atomic percentage). EDS analysis usually involves the generation of an X-ray spectrum from the entire scan area of the SEM. The elemental analyses of the synthesized $\mathrm{TiO}_{2}$ nanomaterials are clearly shown below in figures 9, 10 and 11. The EDS results provided evidences that the required phase of titanium $(\mathrm{Ti})$, chlorine $(\mathrm{Cl})$ and oxygen (O) were present in the sample at calcination temperature of $250^{\circ} \mathrm{C}$. In addition to this, EDS results provided evidences that the required phase of titanium (Ti) and oxygen (O) were present in the sample at calcination temperatures of $400^{\circ} \mathrm{C}$ and $600^{\circ} \mathrm{C}$. The figure 9 shows the presence of chlorine $(\mathrm{Cl})$ phase in the sample at calcination temperature of $250^{\circ} \mathrm{C}$ as shown in table 2 . This indicates that at low calcination temperature, the chlorine is not removed completely. The chlorine atom occurred in the sample comes from titanium tetra chloride $\left(\mathrm{TiCl}_{4}\right)$ solution.

As observed from table 2, when the calcination temperature increases from $250^{\circ} \mathrm{C}$ to $600^{\circ} \mathrm{C}$, the titanium atomic percentage yield decreases while the oxygen atomic percentage yield increases. In relation to this, the theoretical yields of titanium and oxygen are given by $33.33 \%$ and $66.67 \%$ respectively. Again from the same table 2 it is observed that the theoretical percentage yields of titanium and oxygen almost matches with percentage yields of titanium and oxygen obtained at calcination temperature $400^{\circ} \mathrm{C}$. 


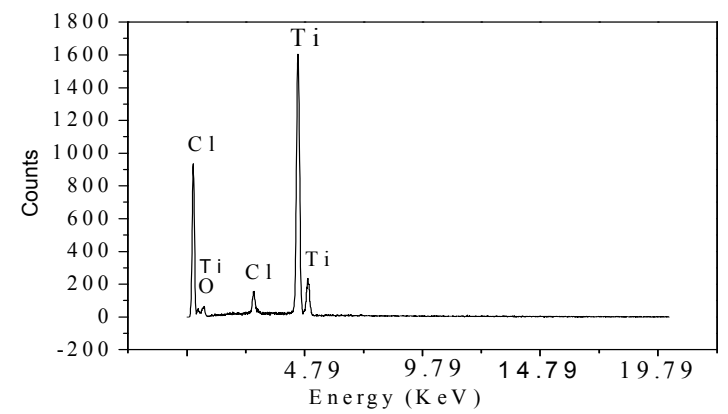

Figure 9. The energy dispersive $x$-ray spectroscopy (EDS) spectrum of $\mathrm{TiO}_{2}$ nanomaterials calcination temperature at $250^{\circ} \mathrm{C}$

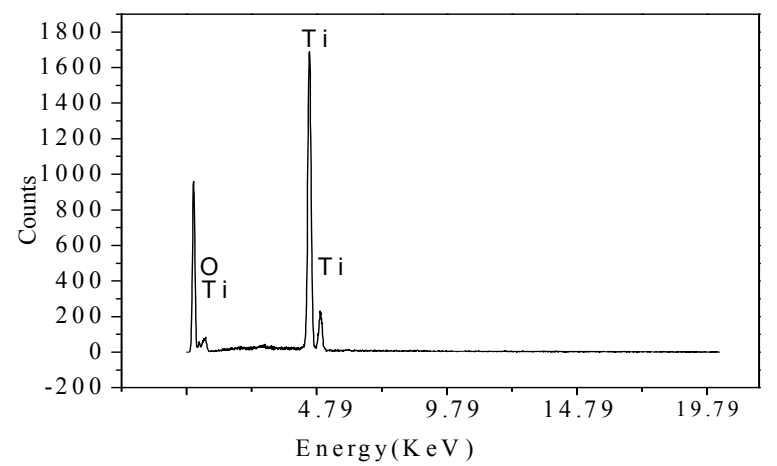

Figure 10. The energy dispersive $x$-ray spectroscopy (EDS) spectrum of $\mathrm{TiO}_{2}$ nanomaterials calcination at temperature at $400^{\circ} \mathrm{C}$

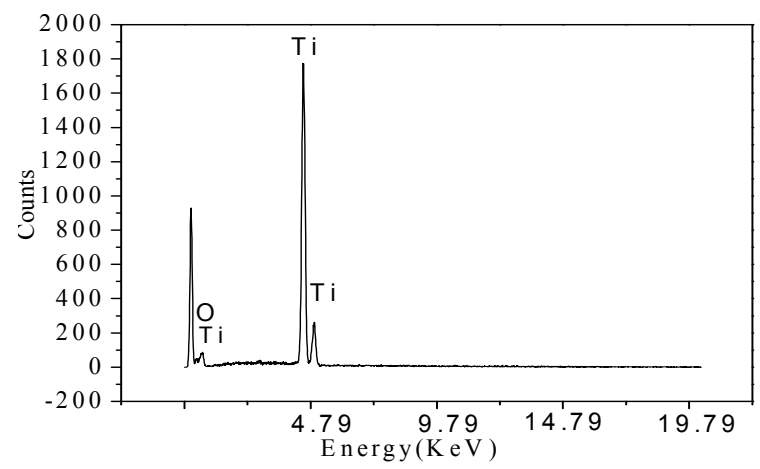

Figure 11. The energy dispersive $x$-ray spectroscopy (EDS) spectrum of $\mathrm{TiO}_{2}$ nanomaterials calcination temperature at $600^{\circ} \mathrm{C}$

Table 2. The energy dispersive $x$-ray spectroscopy (EDS) spectrum of $\mathrm{TiO}_{2}$ nanomaterial results in atomic percent calcination temperatures at $250^{\circ} \mathrm{C}$, $400^{\circ} \mathrm{C}$ and $600^{\circ} \mathrm{C}$

\begin{tabular}{cccc}
\hline $\begin{array}{c}\text { Calcinations temperature } \\
\text { of samples }\end{array}$ & \multicolumn{3}{c}{ Results in atomic percentage } \\
\hline Atom & $\mathrm{Ti}$ & $\mathrm{O}$ & $\mathrm{Cl}$ \\
$250^{\circ} \mathrm{C}$ & 33.34 & 64.02 & 2.64 \\
$400^{\circ} \mathrm{C}$ & 32.6 & 67.4 & 0 \\
$600^{\circ} \mathrm{C}$ & 31.89 & 68.11 & 0 \\
\hline
\end{tabular}

\section{Conclusions}

$\mathrm{TiO}_{2}$ nanomaterials were synthesized using the most convient ways of synthesizing method known as sol gel synthesis. This method is an ease fabrication method due to low cost and is done at low temperature. This method has various advantages over other methods, such as coprecipation, introducing dopant, molecular scale mixing, and high purity of the precursors and homogeneity of solgel products with high purity physical, morphological and chemical properties.

XRD results showed that when the calcination temperatures increase, the FWHM decrease, the particles size increase and for the three selected temperatures the interesting peak value $(2 \theta)$ are the same $\left(25.31^{\circ}\right)$. As observed from the result of TEM and XRD, in this project work, anatase $\mathrm{TiO}_{2}$ nanomaterial is obtained. UV-Vis spectrometers clearly show that the wavelength corresponding to the absorbance edge of $\mathrm{TiO}_{2}$ nanomaterials with calcination temperatures $250^{\circ} \mathrm{C}, 400^{\circ} \mathrm{C}$ and $600^{\circ} \mathrm{C}$ is the same $(350 \mathrm{~nm})$ and the corresponding energy is $3.54 \mathrm{eV}$.

Transmission electron microscopy clearly showed that the produced micrographs of $\mathrm{TiO}_{2}$ nanomaterials size and shape are polydisperse. The synthesized $\mathrm{TiO}_{2}$ nanopowder average particle sizes obtained from TEM micrographs with calcination temperatures at $250^{\circ} \mathrm{C}, 400^{\circ} \mathrm{C}$ and $600^{\circ} \mathrm{C}$ were found to be $(8.55 \pm 0.25) \mathrm{nm},(13.82 \pm 0.41) \mathrm{nm}$ and $(36.06 \pm 2.03) \mathrm{nm}$ respectively. SEM image clearly showed that the shape of synthesized $\mathrm{TiO}_{2}$ nanomaterials is polygonal structural morphology with small agglomeration that is when temperature increase. EDS results show that at low calcination temperature $\left(250^{\circ} \mathrm{C}\right)$, the chlorine is not removed completely. The atomic percentage yield of oxygen increases while atomic percentage yield of titanium decreases with increasing calcination temperatures.

Generally, as has been observed so far from XRD and TEM, when the calcination temperature increases, the size of $\mathrm{TiO}_{2}$ nanomaterial increases.

\section{Acknowledgements}

The Ministry of Education (MOE) is highly acknowledged for providing me with the necessary financial assistance and for awarding me the study leave. I would like to acknowledge the technical and financial support from Nanoscience Innovation Center at University of Cape Town, iThemba Labs (South Africa) and Nanopowder Africa project.

\section{References}

[1] A. Zaleska, 2008. Characteristics of doped- $\mathrm{TiO}_{2}$ photocatalysts. Physico-Chemical Problems of Mineral Processing. 42: 211-213.

[2] C. Burda, X. Chen, R. Narayanan and M. A. El-Sayed, 2005. Chemistry and properties of nanocrystals of different shapes. Chem. Rev. 105(4):1028-1034.

[3] C. Kusumawardani, K. Indriana, Narsito, 2010. Synthesis of nanocrystalline $\mathrm{N}$-doped $\mathrm{TiO}_{2}$ and its application on high efficiency of dye-sensitized solar cells. Sci. J. UBU., 1: 1-8. 
[4] D. Djouadi, A. Aksas and A. Chelouche, 2011. Structural study of titanium dioxide $\left(\mathrm{TiO}_{2}\right)$ nanopowder prepared by sol gel under hypercritical drying. Moldavian Journal of the Physical Sciences. 10:76-78.

[5] K. M. Reddy, S. V. Manorama, A. R. Reddy, 2002. Band gap studies on anatase titanium dioxide nanoparticles. Materials Chemistry and Physics, 78:29.

[6] M. M. Ba-Abbad, A. A. H. Kadhum, A. B. Mohamad, M. S. Takriff, K. Sopian, 2012. Synthesis and catalytic activity of $\mathrm{TiO}_{2}$ nanoparticles for photochemical oxidation of concentrated chlorophenols under direct solar radiation. International Journal Electro-chemical Scince.7: 48714888 .

[7] J. Wang, B. Mao, J. L. Gole and C. Burda, 2010. Visiblelight-driven reversible and switchable hydrophobic to hydrophilic nitrogen doped titania surfaces: correlation with photocatalysis. Nanoscale. 2: 2257-2261.
[8] N. Shahruz, and M. M. Hossian, 2011. Synthesis and size control of $\mathrm{TiO}_{2}$ photocatalyst nanoparticles preparation using sol-gel method. World Appl. Sci. J., 12(11): 1981-1986.

[9] O. Salata, 2004. Applications of nanoparticles in biology and medicine. Journal of Nanobiotechnology. 2:3.

[10] R. Vijayalakshmi and V. Rajendran, 2012. Synthesis and characterization of nano titanium dioxide via different methods. Arch. Appl. Sci., 4 (2):1183-1190.

[11] Y. Bessekhouad, D. Robert, and J.V. Weber, 2003. Preparation of $\mathrm{TiO}_{2}$ nanoparticles by sol-gel route. International Journal of photo-energy. 5:154-155.

[12] Y. Han, H. S. Kim and H. Kim, 2012. Relationship between synthesis conditions and photocatalytic activity of nanocrystalline $\mathrm{TiO}_{2}$. Journal of nanomaterials. Pp. 2-4. 